\title{
Principles of septal correction
}

\author{
A. H. Marshall, F.R.C.S., M. N. Johnston, F.R.C.S., N. S. Jones, M.D., F.R.C.S.
}

\begin{abstract}
The operation of septoplasty is often given to junior surgeons to perform and dismissed as a simple procedure. This can lead to unsatisfactory results with unnecessary morbidity for the patient and disillusionment for the surgeon. Trainee surgeons feel that the operation of septoplasty is poorly taught. Some common problems encountered during septal surgery are described and a variety of surgical solutions are offered.
\end{abstract}

Key words: Nasal Septum; Surgical Procedures, Operative

\section{Introduction}

The septoplasty technique is on the curriculum to be taught and undertaken in the UK in the first year as a specialist registrar in otolaryngology and it is often dismissed as a simple procedure. According to trainees septoplasty is poorly taught and should not be considered as a simple procedure in which one operation fits all. ${ }^{1}$ The competent septal surgeon should have a range of techniques at their disposal to get the best operative result.

Previous authors have described their operative technique $^{2-5}$ inferring that only one approach is necessary for all septal deviations. Others have tried to classify all septal deviations and suggest operative strategies to apply to these cases. ${ }^{6,7}$

Different techniques for re-shaping bent sections of cartilage include morselization ${ }^{5,8,9}$ or incising cartilage in various ways. ${ }^{10-12}$ The possibility of laser re-shaping has been explored, ${ }^{13,14}$ but is yet to find its way into clinical practice. It is thought that incision techniques alone are insufficient for correcting curved cartilage as with time scarring and contraction leads to an unpredictable outcome. Alternative techniques for removing septal deviations include the use of the endoscope,${ }^{15,16}$ powered instrumentation $^{17}$ or laser excision. ${ }^{18}$

The morbidity from septal surgery can be significant, as well as failure to correct the obstruction. Aesthetic change has been noted in up to 21 per cent of patients undergoing septoplasty. ${ }^{19}$ Often this is as a result of inadequate fixation of the septal cartilage when it has been mobilized leading to its posteriorinferior rotation and ensuing loss of tip support and sometimes columellar retraction. ${ }^{20}$ The need for twopoint fixation of the nasal septum to avoid such complications has been discussed previously. ${ }^{21} \mathrm{~A}$ common mistake is to underestimate the extent of any bend in the septum giving the patient an average result when it might have been excellent. Stucker reported a re-operation rate of 15-20 per cent in this group. ${ }^{22}$ An accurate pre-operative assessment is essential, to assess the need for cartilage to be harvested from another source and to decide whether an external approach is needed.

The aim of this paper is to describe how different septal deformities can be corrected whilst minimizing morbidity.

\section{Minor internal mid-cartilage deviation}

This is for septal deformities when the dorsal cartilage is straight and the columella is central with good nasal tip projection. The limited submucous resection is approached via a Killian incision 4-5 $\mathrm{mm}$ behind the mucocutaneous junction on the convex surface (the subperichondrial plane is easily found here, whereas the mucoperichondrial plane is much more adherent further forward). The chondrotomy is placed just anterior to the defect and the subperichondrial plane developed on both sides. The obstructing portion is excised ensuring that at least a $5 \mathrm{~mm}$ strut is left in the columella and superiorly to support the dorsum. The mucoperichondrial flap is replaced and quilting mattress sutures (3/0 vicryl) are placed through and through to maintain position and close the dead space.

\section{Anteriorly dislocated septum}

A very fine anterior deflection $(<3 \mathrm{~mm})$ may be dealt with by shaving the anterior edge of the quadrilateral cartilage, as long as the length of the cartilage is not reduced otherwise columella retraction may occur. 
If the anterior deflection is larger, a hemitransfixion incision onto the anterior end of the dislocated septum is performed and it is freed from the spine. Once the mucoperichondrial flap has been raised on either side of the septum (quadrilateral cartilage, vomer, perpendicular plate of the ethmoid), the strong fibres that join the quadrilateral cartilage to the maxillary spine are cut using a size 15 blade directly onto the bony spine, so as not to shorten the anterior strut. The mucosa, but not the periosteum, is then lifted off the spine and maxillary crest on either side. It is important to mobilize the soft tissue as well, as this can prevent the freed septal cartilage from staying in its new position. A pocket in the columella will partially help the septum remain in the midline. ${ }^{23}$ Curved blunt-ended scissors are useful to make this pocket, which should extend from the spine right to the tip of the septum. There are some superior soft tissue strands, which can prevent the septum being transferred to the midline, and while these look insignificant, if they are left intact they will prevent the septum being positioned correctly. The freed anterior part of cartilage should be secured to the periosteum of the maxillary spine with a mattress suture ( $3 / 0$ vicryl), as a single bite if pulled too taut it would cut through the cartilage. Every effort is made to rotate the quadrilateral cartilage upwards and forwards on the spine, 3/0 vicryl is used to secure the cartilage into the columella pocket (Figure 1).

If the deflection is more posterior or gradual, a posterior chondrotomy is performed to free the quadrilateral cartilage from the vomer and ethmoid. It is important that about $4 \mathrm{~mm}$ of contiguous cartilage is left superiorly in order to avoid a loss of dorsal support. It is worth noting if the vertical plate of the ethmoid or the vomer is angled these may place a rotational torque on any remaining connection to the quadrilateral cartilage and cause the cartilage to return to its old position. Normally the vertical plate of the ethmoid or vomer can be reduced to the midline by fracturing them with a small digit or the tip of the Killian speculum. The mobilized cartilage should stay comfortably in its new position otherwise the operation will not work well, as any remaining torque on the cartilage will result in the cartilage returning to its original position. Even if the septum is stitched onto the maxillary spine if there is any tension remaining within the cartilage it is likely to return to the position it was in before it was sutured.
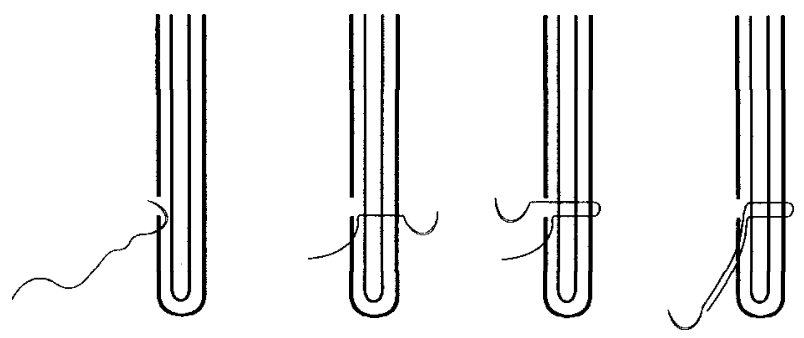

FIG. 1

Suturing technique to secure caudal edge of septum into columella pocket.

\section{Anterior vertical fracture}

There are two main types of anterior fracture: those where the segments of septal cartilage are still straight despite the acute angle of the fracture, and those deformities that have an integral inherent cartilaginous bend.

\section{Anterior isolated vertical deflection}

The fracture line can be incised and the cartilage placed in a columella pocket. ${ }^{23}$ At least $4 \mathrm{~mm}$ of contiguous cartilage should be left superiorly to prevent supratip depression.

A figure of ' 8 ' stitch will stop the anterior segment from falling back and overlapping the posterior segment. The cross of the ' 8 ' should be between the cartilages and it should not be loose (Figure 2) to stop the fragments over-riding one another.

A very anterior vertical fracture may be stabilized after incision through the old fracture-line and stabilization by a baton of cartilage. The baton is secured in place by at least two $4 / 0$ prolene sutures placed through the baton on either side of the fracture (Figure 3).

\section{Inherent bend in cartilage}

When there is an inherent bend in the cartilage as well as the fracture there will be loss of tip support (Figure 4). There are three options:

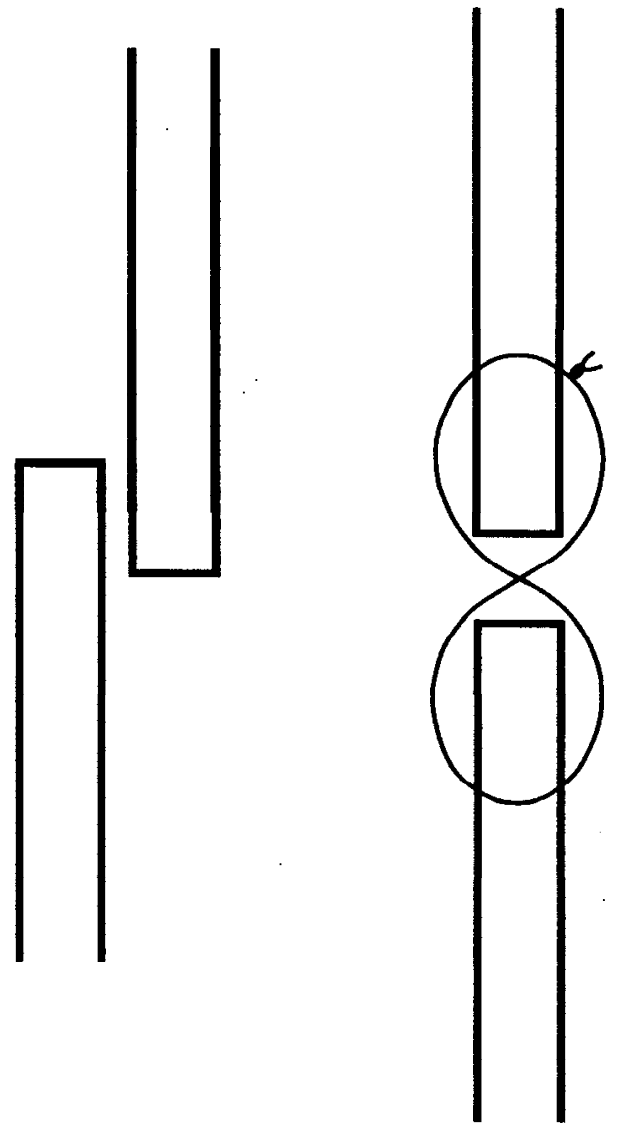

FIG. 2

Figure of ' 8 ' stitch to prevent overlapping. 


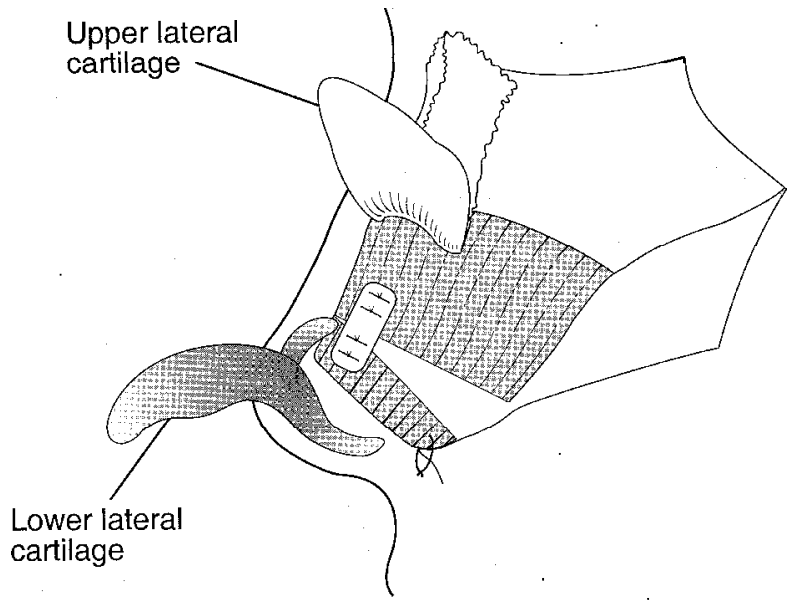

FIG. 3

Baton graft to stabilize incised vertical fracture upper and lower lateral cartilages rotated for illustrative purposes.

(1) The safest is to disguise any deformity by excising the maximum convexity of the septum using a 15 blade to help improve the airway, and to disguise any dorsal deformity with a graft (Figure 5). A dorsal graft can be placed to fill in the supratip deformity, but these measures will not help to 'open' nasolabial angle that will often be present with a crumpled septum. This is particularly undesirable in a man and the I-beam technique is preferable (see later in text).

(2) The second method is to use a cartilage baton that may be sutured to the concave side of the septum after it has been partially incised. The baton will help prevent it scarring up and returning to its original position. If this is not enough to restore the dorsal contour, the supratip depression can then be disguised with a free cartilage graft over the dorsum as long as the underlying septum is stable with two points of fixation.

(3) The third approach is to remove the cartilage and harvest conchal cartilage and laminate the cartilage with several $4 / 0$ prolene sutures, in

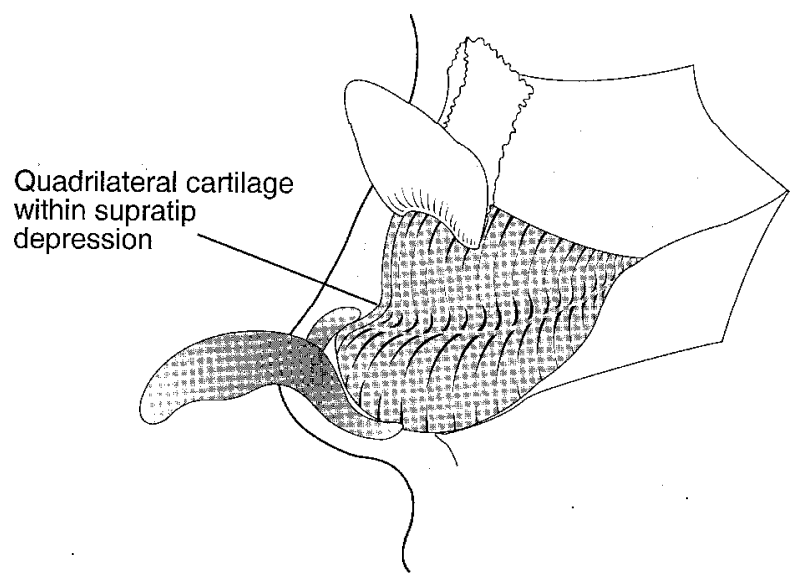

FIG. 4

Inherent bend of quadrilateral cartilage.

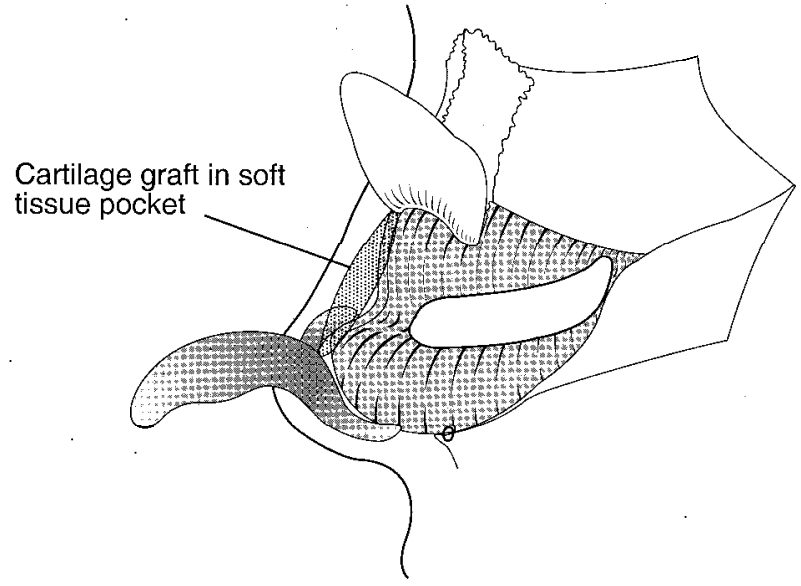

FIG. 5

Camouflage graft, harvested from septum, disguising supratip deformity.

order to make them straight. ${ }^{21}$ These must be of sufficient length to provide tip projection and dorsal support to avoid the tip rotating up and backwards to leave an open nasolabial angle that is particularly undesirable in a man. They are fixed at two points as described in Figure 6: an anterior strut from the maxillary spine in a columella pocket to maintain tip support, and a superior buttress from the superior remains of the quadrilateral cartilage or edge of the chondrotomy (using a 'figure of eight' $4 / 0$ prolene suture) to the anterior strut to provide support.

\section{Anterior vertical fracture}

A more severe anterior vertical fracture may cause the septum to concertina with the nasal tip rotating up as well as loss of support. The most effective way is to remove the whole septum and replace the dorsum with a laminated strut sandwiched between the upper lateral cartilages for extra support (Figure 7 ). If there is little remaining of the maxillary spine a long laminated graft can be placed in a soft tissue pocket through an external rhinoplasty approach to provide adequate tip projection. This does not require suturing to the maxillary spine as it sits in a soft tissue pocket in front of it. The graft is harvested from the whole length of the anterior part of the conchal bowl in order to provide sufficient length. After the anterior and dorsal struts have been sutured together, the feet of the media crura are 'hitched-up' onto the anterior strut to help tip projection. This is called the I-beam technique and was taught to the senior author by Dr Daniel Simmen of Zurich.

\section{Intrinsic bend with loss of supratip support}

The deformed cartilage is defined and it is partially incised on its concave side. Sometimes this is enough to get the septum straight, but unfortunately as it heals it may scar on that side and the deformity return. To prevent this scarring from occurring a 


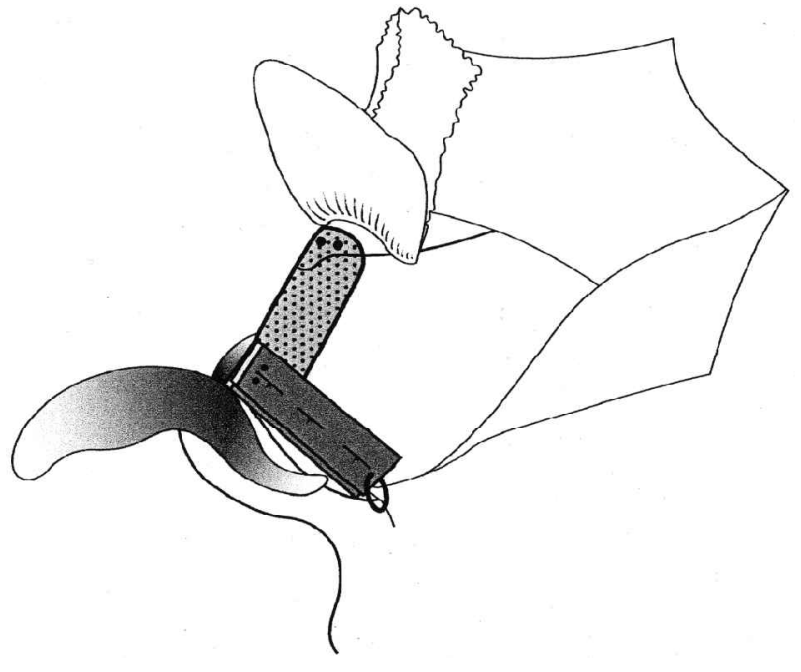

FIG. 6

Laminated conchal cartilage strut fixed at two points.

baton is used on the convex side and sutured in place with prolene sutures to reduce the effect of scarring. This will strengthen the already previously weakened tip support.

If the inherent bend is too great then it is better to remove the cartilage and use an I-beam of laminated conchal cartilage in a soft tissue pocket in front of the maxillary spine via an external rhinoplasty approach (Figure 7). A dorsal strut along with an onlay boat shaped graft may be needed to provide dorsal support and disguise any dorsal defect.

\section{Horizontal fracture with loss of tip support}

The horizontal fracture line should be excised leaving a dorsal strut to the nasal tip (Figures 8,9). The inferior segment of cartilage is retrieved to allow as much length as possible to provide a columella strut graft to support the medial crura and secured using two points of fixation. This is why it is

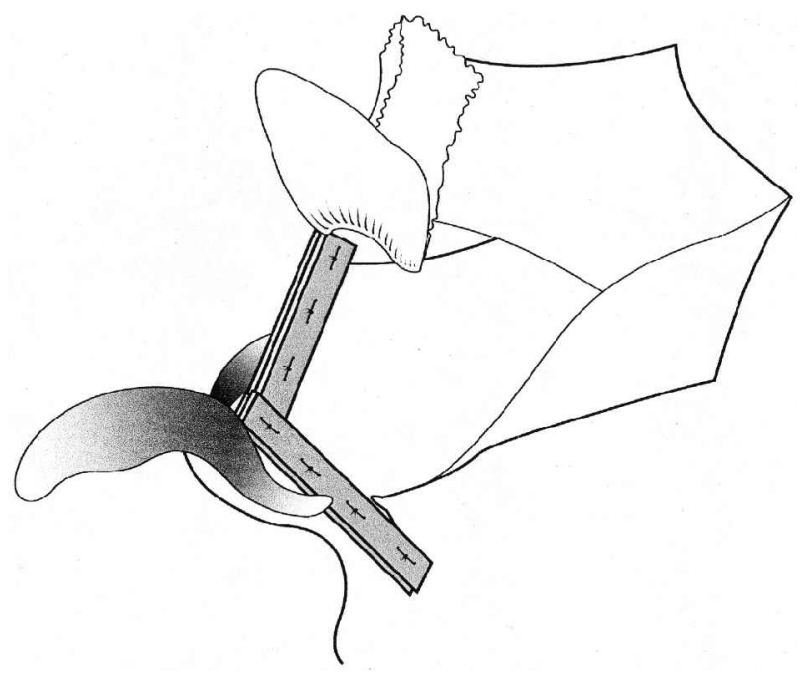

FIG. 7

'I-beam' with laminated dorsal strut to replace quadrilateral cartilage.

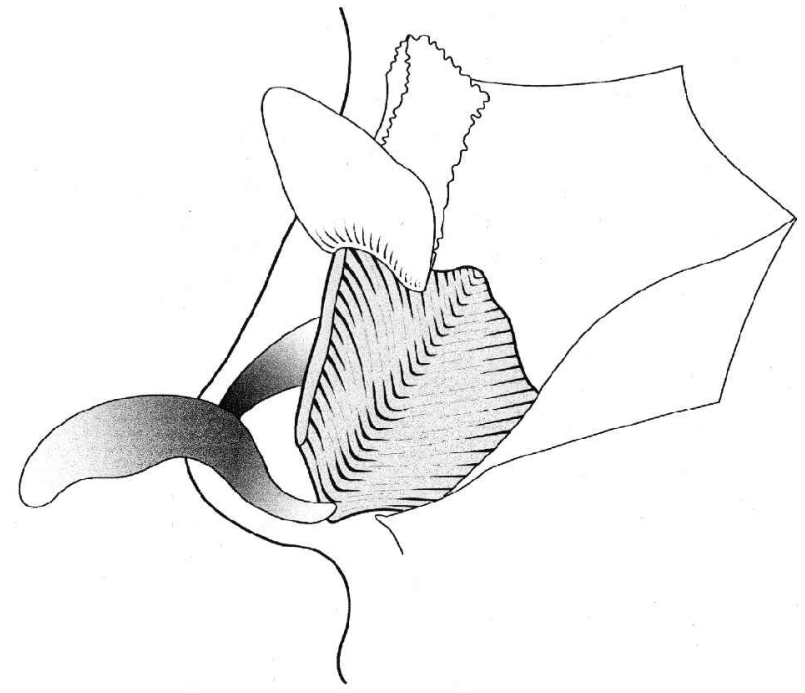

FIG. 8

Horizontal fracture of nasal septum.

important to dissect the whole nasal septum and not to make any chondrotomy before judging what should be done. To make an incision in the cartilage would compromise the length of cartilage that could be harvested. This allows for good tip support and projection.

\section{Vertical loss of height in the septum}

It is safest to deal conservatively with any internal obstruction and remove enough cartilage to improve the airway, but not so much that dorsal support is impaired any further. Any supratip depression can then be disguised with a free cartilage graft using either pieces from the septum or the conchal bowl, as long as there is a good underlying cartilage scaffold, otherwise the patient will have an open nasolabial angle and may have valve collapse. A dorsal defect can be disguised with cartilage that is laminated and sutured together with $6 / 0$ prolene. Using an inter-

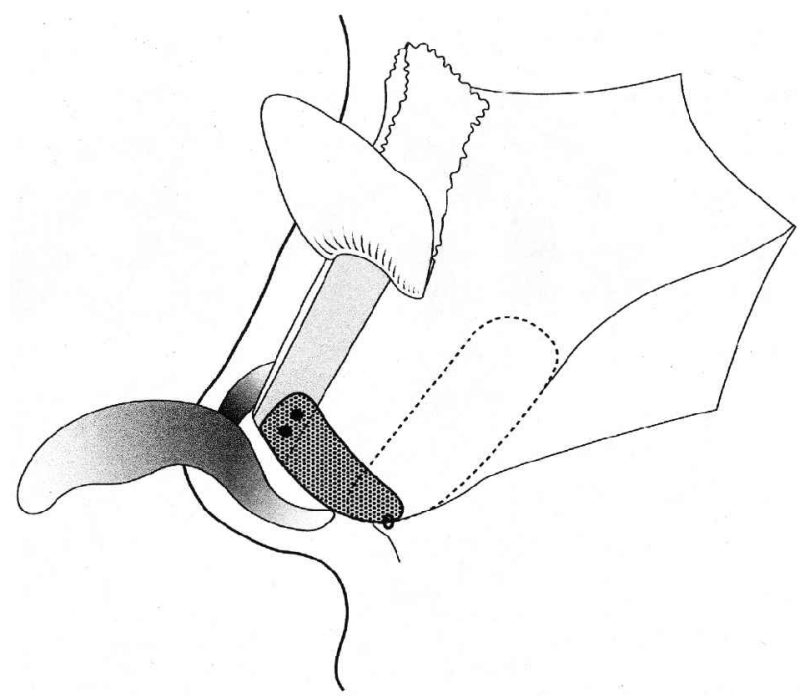

FIG. 9

Excised horizontal fracture with columella strut graft. 

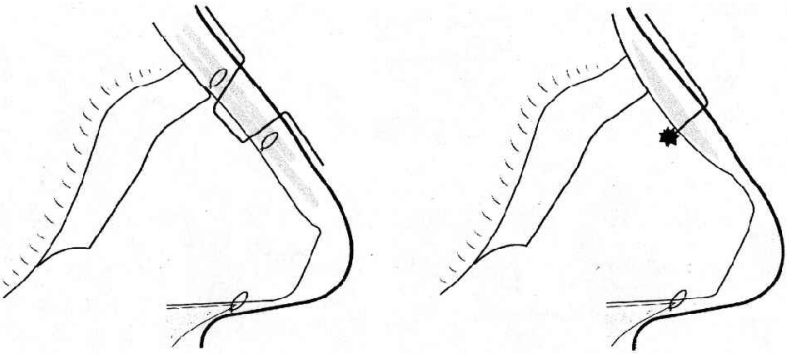

FIG. 10

Stitching techniques to secure dorsal free grafts.

cartilagenous incision very curved scissors (Knapp scissors), are used to develop a dorsal pocket. If the cartilage graft shows any tendency to wander, it is best secured by a percutaneous vicryl rapide suture. This stitch can be single with a knot tied before piercing the graft in position from below. If the graft shows any tendency to rotate, the suture can be initially inserted transcutaneously before being retrieved in the nose and then through the cartilage and skin again. The cutaneous suture is secured in the skin with micropore for seven days and when the tape is removed the suture cut flush to the skin (Figure 10).

\section{Conclusion}

If two points of fixation are obtained and an adequate amount of cartilage is present, then it is possible to maintain tip projection and the dorsal contour, no matter how much mobilization of the septum is required. More conservative techniques are associated with reduced morbidity, but the effort needed to harvest conchal cartilage should not compromise it being taken when this is required to obtain good tip projection. If dorsal asymmetry remains after the septal cartilage has been centred then any defect is best disguised with a free cartilage graft or laminating it with a free cartilage graft to straighten it. The most common fault is to overlook, or only partially correct, the amount of tip and dorsal projection towards the tip as to do so is not only time consuming but it requires cartilage to be taken from one or both conchal bowls.

\section{Main principles}

1. Do not make a chondrotomy incision until the mucoperichondrial planes have been dissected on both sides and there is a clear plan as to how the septal deformity will be corrected.

2. Two points of fixation are required in order to prevent the cartilage from rotating inferiorly or posteriorly with a loss of supratip or tip support.

3 . An adequate height and length of cartilage is needed to support the nasal dorsum and any shortfall will often result in inadequate tip projection.

4. If there is not enough quadrilateral cartilage present for augmentation then a conchal cartilage graft can be laminated to form a strong straight strut. A laminated dorsal strut can be used to help improve nasal contour and tip projection.
Training in septal surgery is often inadequate and it is often implied that one surgical technique will suffice in all circumstances

- The operation may be technically demanding and different techniques are necessary if the functional and aesthetic outcome is to be favourable

- This paper provides a review of differing methods available for mobilizing and securing the septum

5. Before suturing it, the septum should lie in the midline without any tendency to return to its original position.

6. A residual tilt from the vertical plate of the ethmoid and vomer can place torque on its remaining connection with the septal cartilage in spite of it being mobilized. It is worth correcting any ethmoid/ vomerine displacement before suturing the quadrilateral cartilage to minimize any influence its displacement might have on the septum or nasal bones.

\section{Acknowledgements}

The authors would like to thank Lyndon Cochrane for his assistance in preparing the illustrations for this manuscript.

\section{References}

1 Oakley RJ, El-Alami M, Rowe-Jones JM. Septal surgery: were you trained? $R$ Coll Surg Bull 2003.;84:15-7

2 Tepan MG. Septoplasty - a new technique. J Laryngol Otol 1970;84:1133-46

3 Maran AGD. Septoplasty. J Laryngol Otol 1974;88:393-405

4 Mantovani M, Mazzola RF, Cioccarelli MG. The back and forth septoplasty. Plast Reconstr Surg 1996;97:40-4

5 Urquhart AC, Bersalona F. Septoplasty: correcting the nasal valve. Laryngoscope 1997;107:537-9

6 Guyuron B, Uzzo CD, Scull H. A practical classification of septonasal deviation and an effective guide to septal surgery. Plast Reconstr Surg 1999;104:2202-9

7 Sciuto S, Bernardeschi D. Excision and replacement of nasal septum in aesthetic and functional nose surgery: setting criteria and establishing indications. Rhinology 1999;37:74-9

8 Healy GB. An approach to the nasal septum in children. Laryngoscope 1986;96:1239-42

9 Rubin FF. Permanent change in shape of cartilage by morselisation. Facial Plast Reconstr Surg 1969;89:602-8

10 Min YG, Chung JW. Cartilaginous incisions in septoplasty. ORL 1996;58:51-4

11 Murakami WT, Wong LW, Davidson TM. Applications of the biomechanical behaviour of cartilage to nasal septoplastic surgery. Laryngoscope 1982;92:300-9

12 Sessions RB, Wenig BL. The nasal septum. In: Krause CJ, ed. Otolaryngology-Head and Neck Surgery. St Louis: CV Mosby, 1986;673-97

13 Sviridov A, Sobol E, Jones N, Lowe J. The effect of holium laser radiation on stress, temperature and structure of cartilage. Lasers Med Sci 1998;13:73-7

14 Jones N, Sviridov A, Sobol E, Omelchenko A, Lowe J. A prospective randomised study of laser reshaping of cartilage in vivo. Lasers Med Sci 2001;16:284-90

15 Nayak DR, Balakrishnan R, Murthy D. An endoscopic approach to the deviated nasal septum - a preliminary study. J Laryngol Otol 1998;112:934-9 
16 Hwang PH, McLaughlin RB, Lanza DC, Kennedy DW. Endoscopic septoplasty: indications, technique, and results. Otolaryngol Head Neck Surg 1999;120:678-82

17 Becker DG, Park SS, Toriumi DM. Powered instrumentation for rhinoplasty and septoplasty. Otolaryngol Clin North Am 1999;32:683-93

18 Kanami YV, Pandraud L, Bougara A. Laser-assisted outpatient septoplasty: results in 703 patients. Otolaryngol Head Neck Surg 2000;122:445-9

19 Vuyk HD, Langenhuijsen KJ. Aesthetic sequelae of septoplasty. Clin Otol 1997;22:226-32

20 Schwab JA, Pirsig W. Complications of septal surgery. Facial Plast Surg 1997;13:3-14

21 Jones NS. Principles for correcting the septum in septorhinoplasty: Two - point fixation. J Laryngol Otol 1999;113:405-12

22 Stucker FJ. Management of the scoliotic nose. Laryngoscope 1982;92:128-33
23 Kenyon GS, Kalan A, Jones NS. Columnelloplasty: a new suture technique to correct caudal septal cartilage dislocation. Clin Otol 2002;27:188

Address for correspondence:

Professor N. S. Jones,

Department of Otorhinolaryngology Head and Neck Surgery,

University Hospital,

Nottingham NG7 2UH,

UK.

Professor N. S. Jones takes responsibility for the integrity of the content of the paper.

Competing interests: None declared 